Classifications. New York, NY: Springer; 1979.

27. Moro ML, Sommella L, Gialli M, Tavanti L, Ciolli L, Masini, R, et al. Surgical infections surveillance: results of a six-month incidence study in two Italian hospitals. Eur J Epidemiol 1991;7:641-648.

28. Holzheimer RG, Haupt W, Thiede A, Schwarzkopf A. The challenge of postoperative infections: does the surgeon make a difference? Infect Control Hosp Epidemiol 1997;18:449-456.

29. Gaynes RP. Surveillance of nosocomial infections: a fundamental ingredient for quality. Infect Control Hosp Epidemiol 1997;18:475-478.

30. Archibald LK, Gaynes RP. Hospital-acquired infections in the United States. The importance of interhospital comparisons. Infect Dis Clin North Am 1997;11:245-255.

31. Gross PA. Striving for benchmark infection rates: progress in control for patient mix. Am J Med 1991;91 (suppl 3B):16-20.
32. Sijbrandij S. Consensus totale heupprothese. Ned Tijdschr Geneesk 1988;132:578-582.

33. Mintjes-de Groot AJ, van Hassel CAN, van Linge RH, Verbrugh HA. Estimation of extra charges, extra nursing procedures and prolongation of stay attributable to hospital-acquired infections. Surveillance and Control of Hospital-Acquired Infections in The Netherlands. Ten-Year Experience in an Acute Care Hospital. Rotterdam, The Netherlands: Erasmus University; 1996. Dissertation.

34. de Haas R, Mintjes-de Groot AJ, Geubbels ELPE, van den Berg JMJ, de Boer AS. Evaluatie van gebruik van surveillanceresultaten binnen de PREZIES-ziekenhuizen. Report no. 212200006. Bilthoven, The Netherlands: National Institute of Public Health and the Environment; Utrecht, The Netherlands: National Organization for Quality Assurance in Hospitals; 1997.

\title{
Nosocomial Endocarditis in the ICU
}

\section{Gina Pugliese, RN, MS Martin S. Favero, PhD}

Gouello and colleagues from the Centre Hospitalier Universitaire, Angers, France, conducted a study to review the ICU experience of patients with admitted or acquired nosocomial endocarditis (NE) defined according to the Duke criteria. The study was a prospective cohort study conducted in a university teaching hospital. The records of 22 patients documented with NE during a 6-year period (19921997) were reviewed.

Twenty-two patients ( 9 women, 13 men) aged 38 to 83 (mean, $65 \pm 9$ ) years had an NE (prevalence of $5 / 1,000$ admissions). For 6 patients, $\mathrm{NE}$ was the reason for the admission to the ICU. For 17 patients, the time elapsed between admission and diagnosis of NE was $39 \pm 25$ days. Sixteen patients were predisposed to infection, and 7 had underlying heart conditions that put them at risk for acute endocarditis: 3 prosthetic valves, 2 valvular diseases, and 2 cardiac pacemakers. In 21 cases ( 1 unknown portal of entry), $\mathrm{NE}$ was the consequence of bacteremia related to a medical or surgical procedure: 11 intravascular devices, 8 surgical wounds, 1 tracheal procedure, and 1 leg ulceration. The bacteriologic agents detected in blood cultures were staphylococci (17), Streptococcus species (2), Pseudomonas aeruginosa (2), and Candida (2).

Fourteen patients underwent echocardiography according to cardiac signs (cardiac failure, new cardiac murmur, or embolic event). For the remaining 8 , echocardiography was performed systematically because of fever and positive blood cultures. The lesions detected by 21 transthoracic and 17 transesophageal echocardiographs were vegetations (19), myocar- dial abscesses (5), and valvular perforation (1). Of 16 surgical indications, only 5 patients underwent surgery, because the others were in too poor condition. The overall mortality was 15 (68\%) of 22 and was directly associated with NE in 8 cases $(36 \% 8)$. Seven patients $(28 \%)$ were discharged 34 days after the diagnosis of endocarditis.

The authors concluded that NE is a frequent nosocomial infection that occurs late in hospitalization. Persistent fever with positive blood cultures is sufficient indication to perform an echocardiogram. The poor prognosis is related to the poor condition of those patients who cannot be referred for surgical treatment.

FROM: Gouello JP, Asfar P, Brenet O, Kouatchet A, Berthelot G, Alquier P. Nosocomial endocarditis in the intensive care unit: an analysis of 22 cases. Crit Care Med 2000;28:377-382. 